\title{
Effects of Selection of Inlet Perturbations, Multiphase and Turbulence Equations on Slug Flow Characteristics Using Altair $^{\circledR}$ AcuSolve ${ }^{\mathrm{TM}}$
}

\author{
Mohammad Sobir Abdul Basith ${ }^{1}$, Nabihah Sallih ${ }^{1,2, *}$, William Pao King Soon ${ }^{1}$, Shinji Thomas Shibano ${ }^{3}$, \\ Ramesh Singh ${ }^{4,5}$ (D) and Mohd Ayub Sulong ${ }^{6}$ (i) \\ 1 Mechanical Engineering Department, Universiti Teknologi PETRONAS (UTP), \\ Seri Iskandar 32610, Perak Darul Ridzuan, Malaysia; mohammad_20001259@utp.edu.my (M.S.A.B.); \\ william.pao@utp.edu.my (W.P.K.S.) \\ 2 UTP-Altair Centre of Excellence, Universiti Teknologi PETRONAS, \\ Seri Iskandar 32610, Perak Darul Ridzuan, Malaysia \\ 3 Altair Engineering, 14F Kyobashi Edogrand, 2-2-1 Kyobashi, Chuoku, Tokyo 104-0031, Japan; \\ shibano@altair.com \\ 4 Center of Advanced Manufacturing and Material Processing, Department of Mechanical Engineering, \\ Faculty of Engineering, University of Malaya, Kuala Lumpur 50603, Malaysia; ramesh79@um.edu.my \\ 5 Faculty of Engineering, Universiti Teknologi Brunei, Tungku Highway, Gadong BE1410, Brunei \\ 6 School of Mechanical Engineering, Universiti Teknologi Malaysia, Johor Bahru 81310, Johor, Malaysia; \\ mayub@utm.my \\ * Correspondence: nabihah.sallih@utp.edu.my
}

Citation: Abdul Basith, M.S.; Sallih, N.; Soon, W.P.K.; Shibano, S.T.; Singh, R.; Sulong, M.A. Effects of Selection of Inlet Perturbations, Multiphase and Turbulence Equations on Slug Flow Characteristics Using Altair ${ }^{\circledR}$ AcuSolve $^{\mathrm{TM}}$. Processes 2021, 9, 2152. https://doi.org/10.3390/pr9122152

Academic Editor: Nicolas Dietrich

Received: 10 August 2021

Accepted: 14 October 2021

Published: 29 November 2021

Publisher's Note: MDPI stays neutral with regard to jurisdictional claims in published maps and institutional affiliations.

Copyright: (c) 2021 by the authors. Licensee MDPI, Basel, Switzerland. This article is an open access article distributed under the terms and conditions of the Creative Commons Attribution (CC BY) license (https:// creativecommons.org/licenses/by/ $4.0 /)$.
Abstract: Selection of inlet perturbations, multiphase equations, and the turbulence equation may affect the development of slug flow using computational fluid dynamic simulation tools. The inlet perturbation, such as sinusoidal and random perturbations, play an essential role in inducing slug formation. Multiphase equations such as volume of fluid and level set methods are used to track and capture the gas-liquid immiscible interface. Similarly, turbulence equations such as Spalart Allmaras (SA), Detached Eddy Simulations (DES), k-omega, and k-epsilon can be used to predict the evolution of turbulence within the flow. At present, no direct comparison is available in the literature on the selection of (i) types of inlet perturbations, (ii) the choice of multiphase equations, and (iii) the turbulence equation on the development of slug flow using the Altair computational package. This article aims to compare the effects of the selection of inlet perturbations, multiphase models and turbulence equations on slug flow characteristics using Altair ${ }^{\circledR}$ AcuSolve $^{\mathrm{TM}}$. The findings by Altair ${ }^{\circledR}$ simulation were compared to published experimental data and simulation works using ANSYS and STAR-CCM+. The slug flow characteristics of interest include slug morphology, a body length-to-diameter ratio, velocity, frequency, and pressure gradient. It was found that the slug flow could be developed for all combinations of settings. Although level set approach in Altair ${ }^{\circledR}$ can track fluid motion successfully, it has a limitation in modelling the convective transport of the multiphase mixture well, unlike ANSYS and STAR-CCM+. Compared to the standard level set method, the coupling of back-and-forth error compensation and correction with the level set function helps to capture the internal boundary more accurately by reducing errors caused by numerical diffusion in the transport of the level set. It was revealed that the Spalart Allmaras turbulence equation could mimic published experimental result better than DES as it produced the closest slug translational velocity. Since the frequency of the slugs for the developed models showed a good agreement with the published data, the models could be sufficient for the investigation of fluid-structure interaction.

Keywords: slug flow; multi-phase flow; computational fluid dynamics; Altair ${ }^{\circledR}$ AcuSolve $^{\mathrm{TM}}$ 


\section{Introduction}

Vibration issue in piping is one of the major causes of downtime, leakage, explosion, and fire in industrial plants. Turbulence within flowing fluid, especially two-phase flows, may results in fluid-induced excitation. Among various flow regimes, slug flow is notorious to cause fluid-induced vibration (FIV) due to its oscillating changes in pressures and phase change hence resulting in a variation of piping amplitudes [1]. In addition, experimental and numerical investigations on dynamic behaviour of slug flow in a horizontal piping system were performed by Wang et al. [2]. They concluded that slug transitional velocity affects the rate of system properties such as mass, stiffness, loading, and damping. As a result of this, an intense vibration occurred after the slug leaves. This demonstrates that the multi-phase fluid flowing inside a piping system can lead to fluid-induced vibration, and hence needs to be carefully investigated and monitored to avoid catastrophic damage at the piping system.

Computational fluid dynamics (CFD) provides an easier and more versatile method for designing and using large-scale computational models to predict complex two-phase flow. In addition, it offers time saving and reduced cost in characterizing the behaviour of the flow [3]. There are several studies on slug flow that utilized CFD as the main tool of the research. Lun et al. [3] were amongst the pioneers in using commercial CFD software to simulate horizontal two-phase flow. CFD for multiphase flows has grown greatly in popularity over the last two decades. Numerous articles have been produced on numerical simulations of gas-liquid flow for horizontal pipelines [4-7].

The general governing equations for CFD are mass conservation law and NavierStokes equations as expressed in Equations (1) and (2), respectively.

$$
\begin{gathered}
\frac{\partial \rho}{\partial t}+\nabla \cdot \rho u=0 \\
\rho\left(\frac{\partial u}{\partial t}+u \cdot \nabla u\right)=\nabla B-\nabla p+\nabla \cdot \tau
\end{gathered}
$$

where $u$ is velocity, $\rho$ is density, $p$ is pressure and $\tau$ is shearing stress and $B$ is body force (e.g., gravity). The "." denotes a dot product between vector while symbol $\nabla$ is the vector of spatial partial derivatives.

An appropriate turbulence equation must be selected to better predict the evolution of turbulence within the flow. The types of turbulence equations are categorized into large-eddy simulation (LES), hybrid approaches and Reynold-Averaged Navier-Stokes (RANS). The general form of turbulence model is expressed in Equation (3).

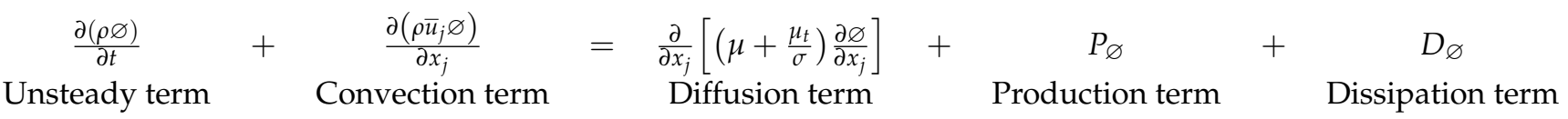

The turbulence model, which is formulated with five different terms, is normally applied in CFD simulations to increase accuracy, and reduce computational time. Given $\varnothing$ as turbulence variables, the unsteady term represents time dependence of turbulent variables while the convection term is a rate of change of turbulent variables due to convection by the mean flow. The transport of turbulent variables due to the summation of material viscosity and eddy viscosity is known as diffusion term. The production term is a production rate of turbulent variables from the mean flow gradient while dissipation term refers to the rate of turbulence variables due to viscous stresses. Table 1 shows the parameters employed for these terms for selected turbulence models. Note that Boussinesq hypothesis is employed in Spalart Allmaras (SA), k-epsilon, and k-omega models and it offers a relatively low-cost computation for the turbulence viscosity $\left(v_{t}=\mu_{t} / \rho\right)$. 
Table 1. Expressions for turbulence terms for selected turbulence models.

\begin{tabular}{ccccc}
\hline Turbulence Model & Turbulence Variables, $\varnothing$ & Turbulence Viscosity, $\boldsymbol{\mu}_{t}$ & Production Terms, $\boldsymbol{P}_{\varnothing}$ & Dissipation Terms, $\boldsymbol{D}_{\varnothing}$ \\
\hline Spalart Allmaras & $\hat{v}$ & $\rho \hat{v} f_{v 1}$ & $P=\rho C_{b 1} \hat{S} \hat{v}$ & $D=-\rho C_{w 1} f_{w}\left(\frac{\hat{v}}{d}\right)^{2}$ \\
k-epsilon & $k$ & $C_{\mu} \frac{k^{2}}{\epsilon}\left(C_{\mu}=0.09\right)$ & $P_{k}=\mu_{t} S^{2}$ & $D_{k}=-\rho \epsilon$ \\
k-omega & $\epsilon$ & $\mu_{t}=C_{\epsilon 1} \frac{\epsilon}{k} P_{k}$ & $D_{\epsilon}=-C_{\epsilon 2} \rho \frac{\epsilon^{2}}{k}$ \\
& $k$ & $P_{k}=\mu_{t} S^{2}$ & $D_{k}=-\rho \beta^{*} k \omega$ \\
\hline
\end{tabular}

Spalart Allmaras is the latest turbulence equation based on one-equation eddy viscosity model developed in 1992. Hence, there is a renewed kind of interest for researchers in CFD field towards SA. It has the advantage of having economic solutions for attached flows and moderately separated flows. It solves a modelled transport equation for the kinematic eddy (turbulent) viscosity [8]. It is also reliable in converging the simulation's iterative process, hence providing a good result to the simulation [9]. Besides SA, detachededdy-simulations (DES), which is a hybrid model of Reynolds-averaged Navier-Stokes (RANS) and large-eddy simulation (LES) can also be used to describe a more accurate flow. It uses RANS method for near wall computation and dynamic LES for a region a bit far from the wall. DES employs the distance to the closest wall as the definition for the length scale which plays a major role in determining the production level and destruction of turbulent viscosity.

There is a number of researchers investigating slug flow behaviour who performed their analysis by employing k-epsilon model as turbulence equation of choice [10-12]. This k-epsilon assumes that the flow is fully turbulent, and the effects of molecular viscosity are negligible [13]. The turbulence equation is popular, and it has been the industry standard for many years because there is such a rich database of results (i.e., simply because it has been around since the early 1970s). The k-epsilon, however, tends to face convergence issue in solving the governing equation. In comparison to k-omega, $\mathrm{k}$-epsilon model yields better predictions for void fraction close to the wall [13]. Unlike k-epsilon, Spalart Allmaras is claimed to provide more stability in computing the governing equation, so the tendency to face convergence issue is decreased [9]. The reason behind this is because Spalart Allmaras model adds only one more equation to represent turbulence viscosity transport, whereas k-epsilon and k-omega models add two more, thus adding complexity/sophistication to the distribution of eddy viscosity. Based on Ref. [14], among the various turbulence modeling methods including the time average (e.g., RANS), space average (e.g., LES) and hybrid model (e.g., DES), the DES approach is the most practical and a fairly accurate turbulence model. Within the context of slug flow simulation, the impact of the selection of turbulence equation on the resultant flow characteristics has not been elucidated yet.

Besides turbulence equation, the selection of multiphase equation is important for fluid with multiple phases to capture the best representation of liquid and gas distribution within the flow. There are a couple of types of multiphase equation available such EulerianLagrangian, Eulerian-Eulerian, volume of fluid (VOF), and level set. For multi-phase flows, the choices of the multiphase models would be reflected in the mass conservation and momentum conservation equations based on the volume fraction of the phases. In this case, an additional transport equation (volume fraction) is used to track the interface between these two phases $(i, j)$ by solving the continuity equation for steady incompressible flow as follows [15]:

$$
\frac{\partial k}{\partial t}+U_{j} \frac{\partial k}{\partial x_{j}}=\tau_{i j} \frac{\partial U_{i}}{\partial x_{j}}-\epsilon+\frac{\partial}{\partial x_{j}}\left[v \frac{\partial k}{\partial x_{j}}-\frac{1}{2} \overline{u_{i}^{\prime} u_{i}^{\prime} u^{\prime}}-\frac{1}{\rho} \overline{p^{\prime} u^{\prime}}\right]
$$

Several CFD packages are available in the market such as Altair ${ }^{\circledR}$ AcuSolve $^{\mathrm{TM}}$, ANSYS ${ }^{\circledR}$ and STAR-CCM+. Altair ${ }^{\circledR}$ AcuSolve ${ }^{\mathrm{TM}}$ is based on finite element method while ANSYS ${ }^{\circledR}$ and STAR-CCM+ are based on finite volume method (FVM). Finite element method (FEM) 
is formulated based on variational principles to solve a CFD problem by minimizing an associated error function or residual. In this method, the problem domain is divided into a set of finite elements which are usually (i) triangles or quadrilaterals for those in a two dimension, and (ii) tetrahedra, hexahedra, pyramids, or wedges in three dimensions. On the other hand, the finite volume method is formulated based on approximate solution of the integral form of the conservation equations. The problem is divided into a set of non-overlapping control volumes referred to as finite volumes, cells, or elements. Despite these differences between finite volume and finite element, the outcomes produced by both methods are expected to be similar.

It should be noted that different CFD packages offer different type of multiphase models. This indirectly influences the use of certain set of equation in the development of multiphase flows within the CFD environment. For example, VOF approach is available in ANSYS $^{\circledR}$ and STAR-CCM+, while Altair ${ }^{\circledR}$ package only offers level set approach. Several researchers who managed to develop slug flow successfully using VOF model include authors in Refs. [4,10,11,16-19]. It was reported that the computational time required to solve the VOF equations is relatively low when compared to that of Eulerian-Eulerian and Eulerian-Lagrangian approaches, making VOF to be utilized more broadly in analyzing two-phase flow $[10,12,20]$. So far, there is no literature available that reports on the use of level set approach using Altair ${ }^{\circledR}$ AcuSolve ${ }^{\mathrm{TM}}$ in the development of two-phase slug flow.

Altair $^{\circledR}$ AcuSolve ${ }^{\mathrm{TM}}$ offers an improvisational form of standard level set known as back-and-forth error compensation and correction (BFECC). It is applied to the multi-field and field interaction model equation to enhance the definition of the volume fraction between liquid and gas. The first stagger governs the interface's transport, while the second stagger controls its sharpness in the standard level set form. The level set with BFECC, on the other hand, includes additional stagger iterations to minimize the amount of diffusion in the solution field. In other words, this predictor-corrector type method is based on the observation that if Equation (5) were solved forward in time for one time step using a numerical integrator and then backward in time for one time step with the same method, the difference between the two copies of the solution gives the information about the numerical error which could be used to further improve the accuracy. It improves the space and time accuracy to the second order by adding level set with BFECC to an existing first order semi-Lagrangian scheme, hence developed a better image presentation than a standard level set [21]. At present, the effectiveness of BFECC implementation with level set multiphase equation on the definition of slug flow morphology has not yet been demonstrated. A passive advection of a scalar field with a given velocity vector field $u(x, t), x \in R^{3}, t \in R_{+}$, is modeled by the transport equation as:

$$
\frac{\partial \varphi}{\partial t}+u \cdot \nabla \varphi=0
$$

Various types of flow regimes, including slug flow, can be induced in CFD environment by setting up appropriate boundary conditions. The obvious setting that affects the resultant flow regime is the input velocity for each phase, as calculated using the following equations:

$$
\begin{aligned}
& \text { Superficial velocity of gas : } u_{G}=\frac{Q_{g}}{\left(\pi D^{2} / 4\right)} \mathrm{m} / \mathrm{s} \\
& \text { Superficial velocity of liquid : } u_{l}=\frac{Q_{l}}{\left(\pi D^{2} / 4\right)} \mathrm{m} / \mathrm{s}
\end{aligned}
$$

where $Q_{g}$ and $Q_{l}$ are flow rates for gas and liquid, respectively.

In addition to that, for successful formation of slug flow, the inlet initial and boundary conditions require appropriate perturbation. There are several approaches in developing the perturbation. Thomas [4] developed slug flow in a horizontal piping system by initializing the phasic distribution in the form of sinusoidal form. This technique was also imitated 
by Ban et al. [12] to determine a transient liquid level at the pipe's inlet cross-section. Equation (8) expresses an example of the function imposed on the interface of gas and liquid at the inlet to create a perturbation.

$$
y_{I}=y_{0}+A_{I} \sin \left(\frac{2 \pi x t}{\rho I}+\pi\right)
$$

The notation $y_{I}$ represents the height of the gas-liquid interface from the reference $y_{0}$ which is the liquid gas interphase. The notation, $A_{I}$ is the liquid level fluctuation amplitude while notation $\rho_{I}$ is the wavelength and $x$ is the mixture velocity.

Imposing a certain amount of disturbance at the inlet helps in developing slug within a short computational time without depending solely on the pipe diameter to length ratio for the formation of slug. Although sinusoidal perturbation can generate the desired slug formation, the frequency of sinusoidal perturbation can affect the resultant frequency of the slug. Consequently, this approach is only applicable for the development of slug flow with a predetermined slug frequency. Instead of sinusoidal perturbation, Schmelter et al. [22] used random perturbation to the interface between liquid and gas phases to avoid premeditating the slug behaviour, especially frequency. The random inlet perturbation can be defined using Equations (9) and (10).

$$
\begin{aligned}
& \Delta y(t)=r(t) \cos (\phi(t)) \\
& \Delta z(t)=r(t) \sin (\phi(t))
\end{aligned}
$$

where $\Delta y(t)$ and $\Delta z(t)$ denote the displacements of the velocity vector in $y$ - and z-directions in polar coordinate, respectively. Based on the findings by Ref. [22], it was shown that the higher the perturbation amplitude, the earlier the slugs occur and if the measurement is taken sufficiently far away from the inlet, the flow pattern shows the same dynamics for different perturbation amplitudes indicating that no specific frequency is imposed by the prescribed perturbation in contrast to the outcome of simulations with sinusoidal perturbations.

So far, to the best of the authors' knowledge, there is no direct comparison in (i) types of inlet perturbations, (ii) choices of multiphase equations, and (iii) turbulence equation on the development of slug flow and their characteristics available in the literature, especially using Altair ${ }^{\circledR}$ computational package. Therefore, this research aims to construct a slug flow model by perturbing each model's inlets with either sinusoidal and random perturbation and applying different types of multiphase and turbulence equations to the models. The models were then directly compared to characterize the parameters of slug behavior, such as slug body length-to-diameter ratio, slug velocity, and pressure gradient.

\section{Methodology}

\subsection{Design of Simulations}

A total of six different combinations of perturbations, multiphase and turbulence equations was developed in this study using Altair ${ }^{\circledR}$ AcuSolve ${ }^{\mathrm{TM}}$ package (see Table 2). The models were developed based on a pipe with a length of $8 \mathrm{~m}$ and internal diameter of $0.074 \mathrm{~m}$, as shown in Figure 1. The liquid-gas system is limited to air-water combination. For benchmarking and comparison purposes, the findings from this study were compared to experimental results published by Ref. [17] and Ansys ${ }^{\circledR}$ and STAR-CCM+ results published by Ref. [10], respectively. It should be noted that the works by Refs. $[10,20] \mathrm{im}-$ plemented VOF and k-epsilon equations while works by Ref. [23] used VOF and k-omega.

\subsection{Multiphase Modeling}

Numerous measures must be taken into consideration depending on the operating conditions such as type of flow regime produced, physical properties and superficial velocity of fluids. Physical properties of water and air at temperature $298 \mathrm{~K}$ and pressure 
101,325 Pa used in the simulation are shown in Table 3 [24]. Based on the combination of the superficial velocity of fluids, the flow regime was identified as slug flow regime.

Table 2. Combinations of perturbations, multiphase and turbulence equations for each model.

\begin{tabular}{cccc}
\hline Model & Perturbation Form & Multiphase Equation & Turbulence Equation \\
\hline Model 1 & Sine & Level set & Spalart Allmaras \\
Model 2 & Random & Level set & Spalart Allmaras \\
Model 3 & Sine & Level set with BFECC & Spalart Allmaras \\
Model 4 & Sine & Level set with BFECC & DES \\
Model 5 & Random & Level set with BFECC & Spalart Allmaras \\
Model 6 & Random & Level set with BFECC & DES \\
\hline
\end{tabular}

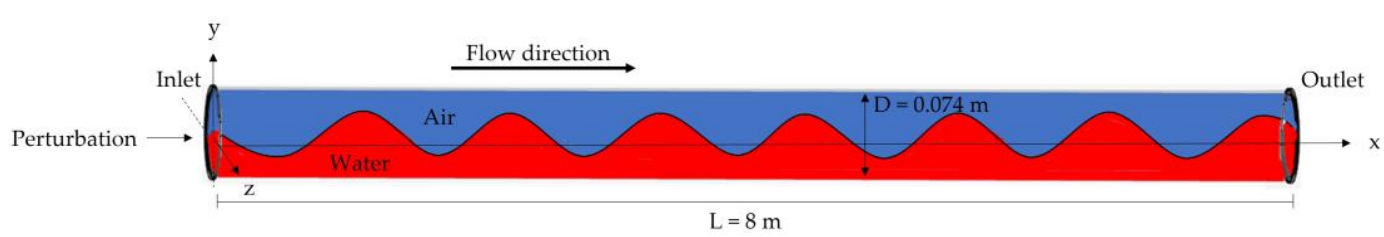

Figure 1. Geometry of the pipe carrying two-phase fluid.

Table 3. Fluid and gas properties employed in the simulation work.

\begin{tabular}{cc}
\hline Input Parameters & Values \\
\hline Water density, $\rho_{l}\left(\mathrm{~kg} / \mathrm{m}^{3}\right)$ & 998.2 \\
Air density, $\rho_{g}\left(\mathrm{~kg} / \mathrm{m}^{3}\right)$ & 1.225 \\
Water viscosity, $\mu(\mathrm{Pa} \mathrm{s})$ & 0.001003 \\
Water surface tension, $\sigma(\mathrm{N} / \mathrm{m})$ & 0.0719404 \\
Superficial velocity of water, $u_{l}(\mathrm{~m} / \mathrm{s})$ & 0.86 \\
Superficial velocity air, $u_{G}(\mathrm{~m} / \mathrm{s})$ & 2.44 \\
\hline
\end{tabular}

\subsection{Mesh Development}

Figure 2 shows the mesh development for the fluid system. The global mesh size was set to $2.0 \mathrm{~mm}$ while the curvature mesh size factor and mesh growth rate were set to 0.0001 and 1.0, respectively. The curvature refinement and maximum sweep angle were adjusted to $10^{\circ}$ and $45^{\circ}$, respectively. The surface mesh of fluid domains was constructed using six boundary layers of tetrahedron elements. The first element height was set to $0.4 \mathrm{~mm}$, with a growth rate of 1.2, resulting in a total layer height of $3.97 \mathrm{~mm}$. A total of 200 layers of mesh extrusion was applied at the mesh along the pipe's length to ensure an equal distribution of the mesh lengthwise. As a result, a total of 940,011 elements and 482,744 nodes were constructed, with a maximum skewness of 0.1 . It should be noted that Altair ${ }^{\circledR}$ AcuSolve ${ }^{\mathrm{TM}}$ is based on FEM, which computes solutions using volume-based discretization, with each surface has linear physical values. Hence, this method can offer a reasonable accuracy in solutions independent of mesh quality (e.g., element shape) unlike other FVM-based CFD codes. In addition, the model obtained a maximum y+ value of 23, thus it is suitable and valid to be used with AcuSolve ${ }^{\mathrm{TM}}$ near-wall function.

\subsection{Mesh Independency Study}

A spatial grid convergence analysis was used to determine the effect of mesh independence on solution results. Three types of mesh refinement, notably coarse, intermediate, and fine mesh models were created. Two parameters were chosen to test the mesh convergence namely averaged pressure gradient and maximum pressure. The element sizes for coarse, intermediate, and fine meshes are $3.47 \mathrm{~mm}, 2.99 \mathrm{~mm}$, and $2.00 \mathrm{~mm}$, respectively. 


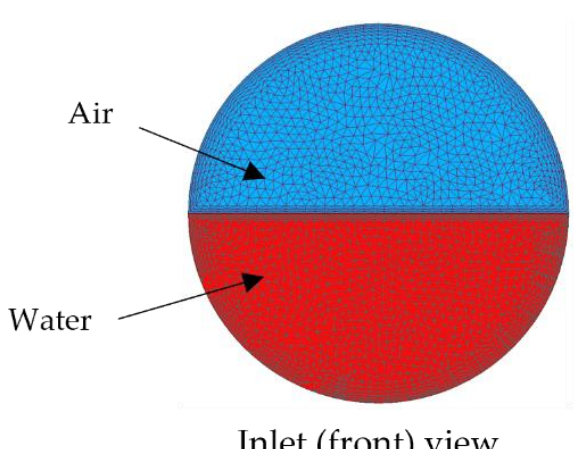

Inlet (front) view

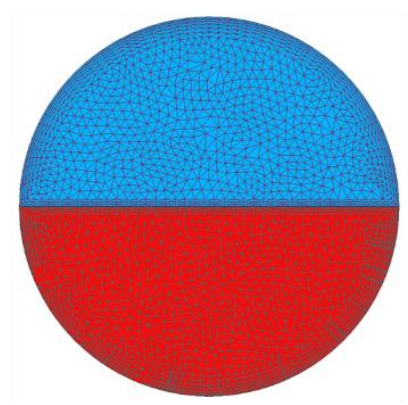

Outlet (rear) view

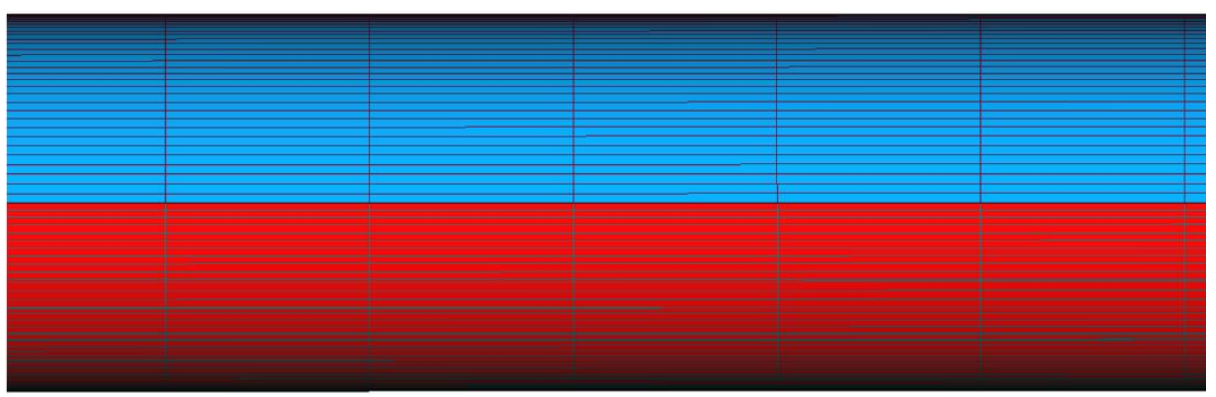

Pipe (lengthwise view)

Figure 2. Mesh development of the piping system.

Following the data collection, Grid Convergence Index (GCI) was calculated using Equation (11). The GCI was used to determine whether the obtained findings are inside the asymptotic range of convergence. In theory, as the grid resolution decreases toward 0 , the numerical solution approaches the true solution. The index can provide a good indication of the percentage deviation owing to mesh discretization. The lower GCI values, the accuracy of the result produced increases [25].

$$
G C I=\frac{F|\varepsilon|}{\left(r^{P}-1\right)}
$$

where

$$
\begin{gathered}
\varepsilon=\frac{f_{2}-f_{1}}{f_{1}} \\
p=\frac{\ln \left(\frac{f_{3}-f_{2}}{f_{2}-f_{1}}\right)}{\ln (r)}
\end{gathered}
$$

Notations $F, \varepsilon, f, r$ and $p$ denote factor of safety, relative error, selected parameter value obtained from simulation, grid refinement ratio and the order of convergence, respectively. Table 4 shows mesh refinement details and convergence criteria for this study. The obtained extrapolated values correspond to the true solution, and they can be used to evaluate the numerical discretization's adequacy.

Table 4. Mesh refinement and convergence criteria.

\begin{tabular}{ccccc}
\hline Mesh Refinement & $\begin{array}{c}\text { Number of } \\
\text { Elements }\end{array}$ & $\begin{array}{c}\text { Maximum Element } \\
\text { Size } \mathbf{( m m )}\end{array}$ & $\begin{array}{c}\text { Averaged Pressure } \\
\text { Gradient } \\
\mathbf{( P a} / \mathbf{m})\end{array}$ & $\begin{array}{c}\text { Maximum Pressure } \\
\mathbf{( K P a )}\end{array}$ \\
\hline Coarse & 349,917 & 3.47 & $f_{1}=-127.49$ & $f_{1}=106.29$ \\
Intermediate & 550,728 & 2.99 & $f_{2}=-140.85$ & $f_{2}=108.730$ \\
$f_{3}=-153.64$ & 112.04 \\
\hline Fine & 940,011 & 2.00 & -153.70 & 112.04 \\
\hline
\end{tabular}


With reference to Figure 3, as the mesh was refined with a constant grid refinement ratio, the values of chosen variables tended to converge. It was observed that the results significantly improved when intermediate mesh and fine mesh replaced the coarse mesh. The percentage of GCI for coarse mesh to intermediate mesh transitions is not suggested to be used as the calculated GCI values are $6.77 \%$ for maximum pressure and $0.03 \%$ for averaged pressure gradient. As a result, coarse mesh is not a realistic option. Hence, fine mesh with 940,011 which produced the lower GCI values was chosen as the main mesh grid refinement for this study as it produced more accurate results.

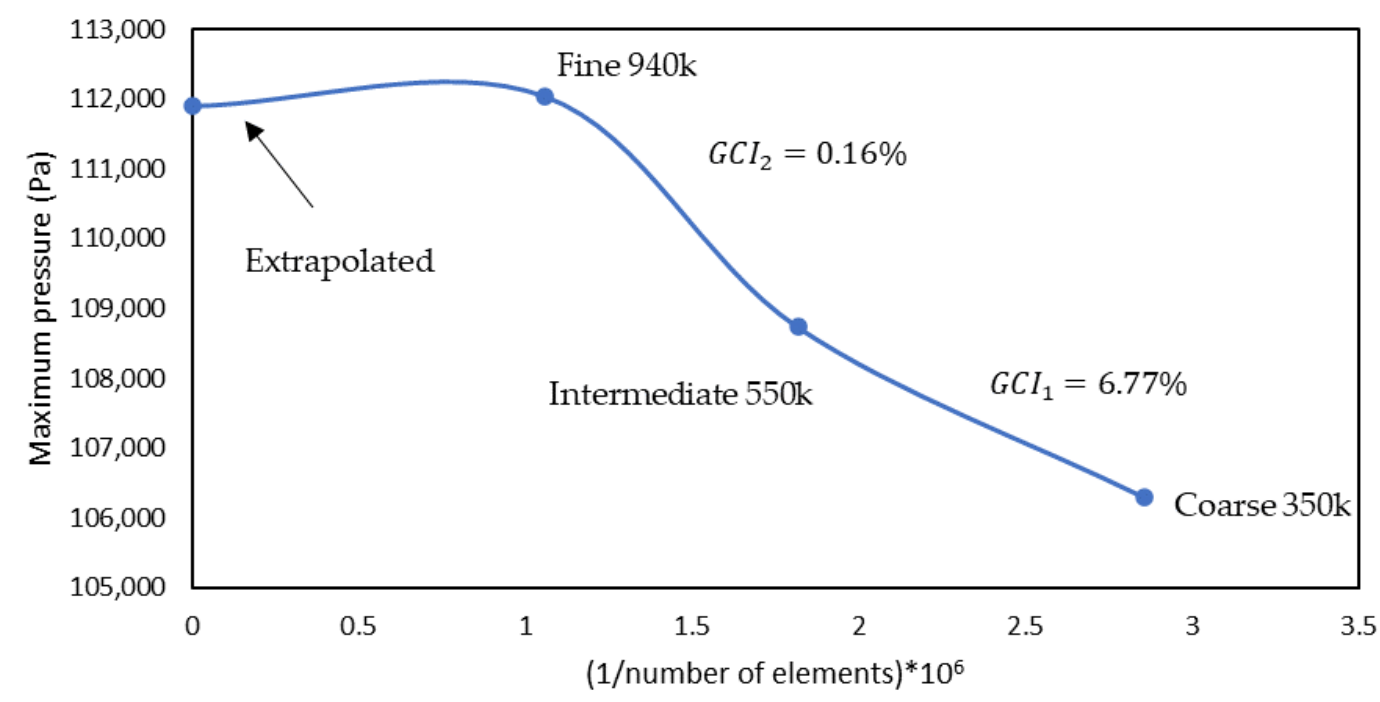

(a)

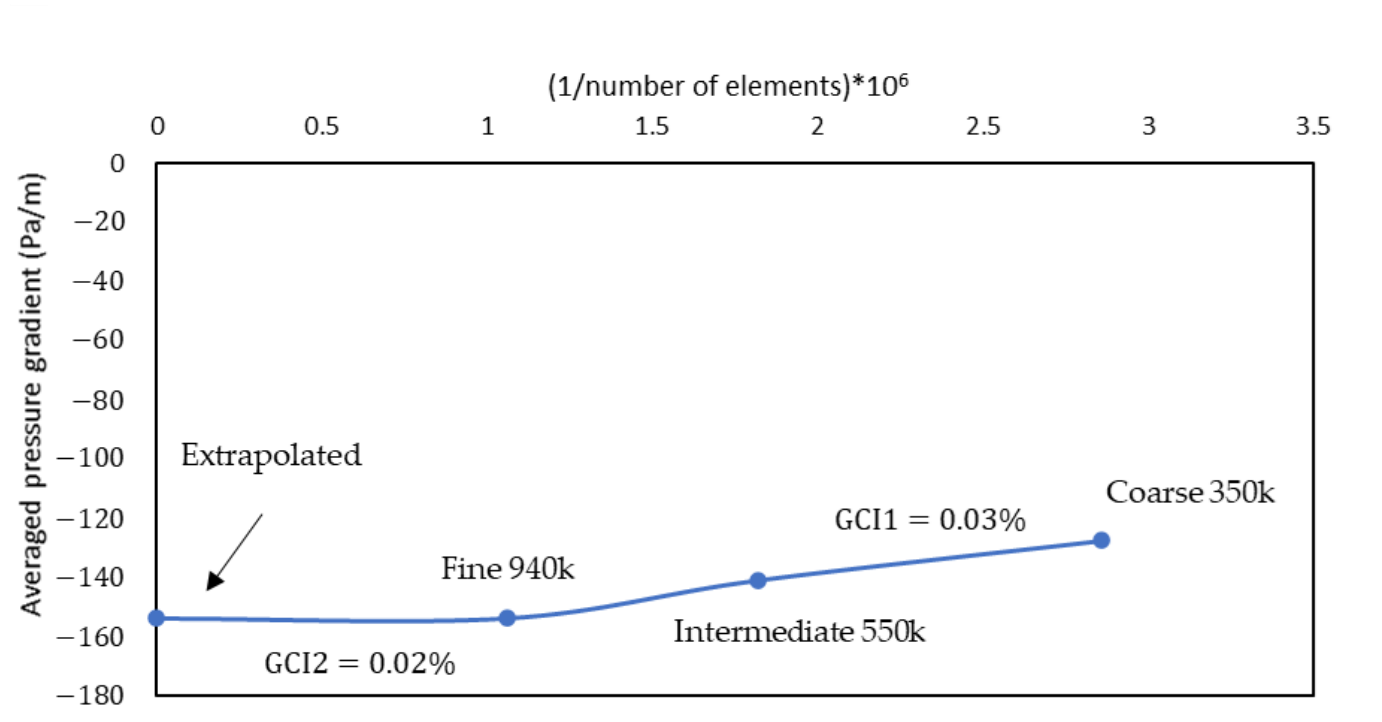

(b)

Figure 3. Mesh independency study: (a) Maximum pressure, and (b) averaged pressure gradient against 1/number of elements.

\subsection{Setting for Boundary Conditions and Inlet Perturbations}

The initial condition was set such that the gas-liquid volume fraction has a 50-50 volume share, with just liquid filling the bottom of the pipeline while gas phase covering the top of the liquid surface. An inlet perturbation was prescribed to the fluid-liquid interface at the inlet of the pipe to create disturbance to the flow, as shown in Figure 4. The mesh at the 
inlet region is set to Arbitrary Lagrangian-Eulerian mesh motion. A guide was created to ensure the movement of fluids interface is bounded within the inlet (Y-Z) plane.

(a)

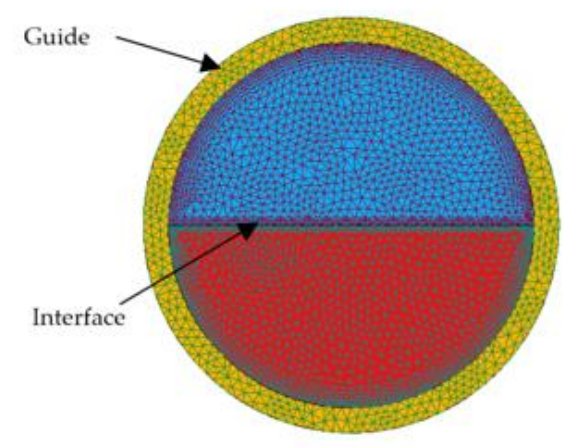

(b)

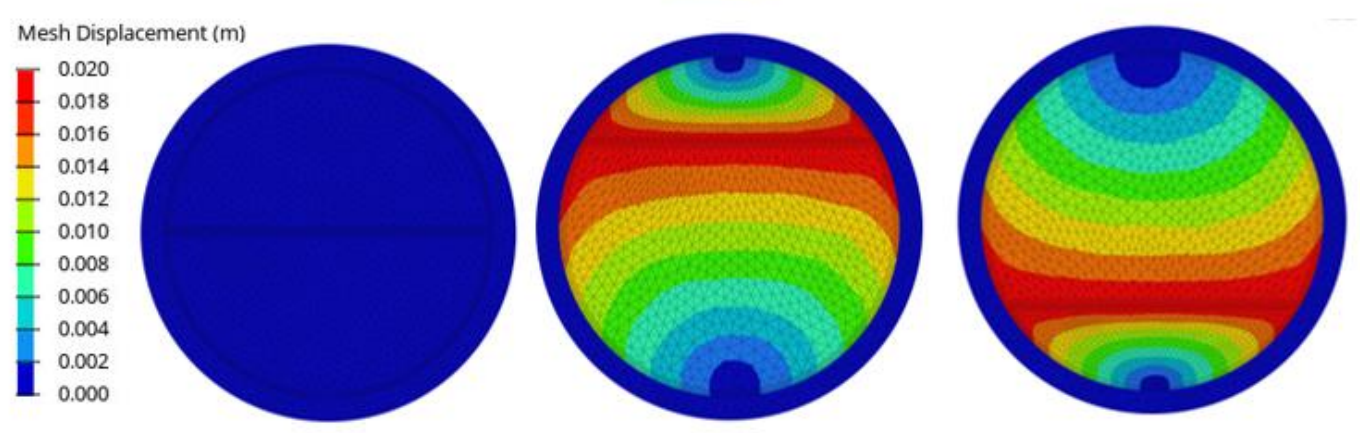

Figure 4. (a) Design of inlet to enable the prescription of perturbation and (b) Mesh motion due to the inlet perturbation.

Equations (8)-(10) were used to describe the sinusoidal and random inlet perturbations, respectively. The random perturbation's amplitude was selected to cover $0.75 \mathrm{D}$ of the cross-section, which is similar to the setup in Ref. [4]. The perturbation time step was set to $0.05 \mathrm{~s}$. It should be noted that a smaller value may cause the model to become unstable, therefore terminating the calculation process prematurely. The outlet of the pipe was set to the constant atmospheric pressure. The walls of the fluids were treated as hydraulically smooth with classical no-slip boundary conditions.

For computational purposes, a constant time step of $0.001 \mathrm{~s}$ with a total physical time of $4 \mathrm{~s}$ were simulated for all models. The set simulation time is adequate to capture the slug initiation and growth.

\subsection{Qualitative Measure of Slug Characteristics}

The investigation on the characteristics of slug flow can be divided into two parts: qualitative and quantitative comparisons. For qualitative comparison, the phases were defined to differentiate air and water volumes. Slug flow is defined by intermittent liquid slugs (slug bodies), which cover a large cross-sectional area of the pipe, supplemented by gas, as shown in Figure 5. The gas and liquid circulate in separate layers in pocket regions to create what is known as Taylor bubbles. The tiny gas bubbles are entrained in the liquid slug body.

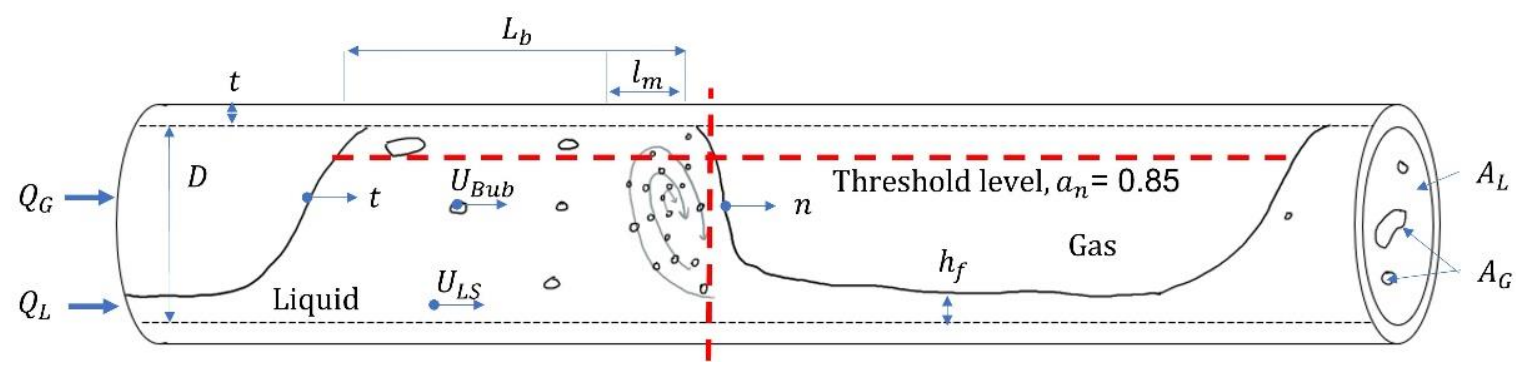

Figure 5. Illustration of slug flow and the notations used to describe flow characteristics. 
Liquid level is the main interest in slug flow as it indicates whether the body of the flow is a slug or not. Threshold, $a_{n}$ is introduced to measure the development of slug flow and it needs to be chosen carefully. Entrained gas bubbles can separate larger slugs if it is too large. Therefore, it should be set high enough to prevent large-amplitude waves from being detected [22]. A number of authors outlined the threshold limit for the liquid level. Montini [26] set the threshold to $a_{n}$ of 0.98 when they characterized as slug flow with the justification that the gas volume fraction tends to zero as a slug body forms, and the discretized gas momentum equation becomes singular as a measure. On the other hand, Manolis [27] used threshold $a_{n}$ of 0.85 and it has been proven to accurately identify slugs by several Water, Air, Sand and Petroleum (WASP) operators [28-30]. Therefore, in this study, threshold $a_{n}$ of 0.85 was selected to indicate the slug's appearance in the post processing. The distribution of gas and liquid within the flow can be identified based on the volume fraction of the fluid system. The range of the types of fluid occupied a cell is between 0 and 1 , where 1 represents that the cell is fully occupied by a particular type of fluid.

\subsection{Quantitative Measures of Slug Characteristics}

For the quantitative measure, slug body length to diameter ratio $\left(L_{b}\right)$, slug velocity $\left(U_{s}\right)$, frequency of slug $\left(f_{s}\right)$, and pressure drop $(\Delta P)$ were characterized, as described in the following sub-sections.

\subsubsection{Slug Velocity}

Slug translational velocity, $U_{s}$ was calculated using Equation (14), based on the same method applied in Ref. [31]. The method uses two locations along with the pipe system, denoted as $x_{1}$ and $x_{2}$, and computes the time required for the slug to travel from $x_{1}$ to $x_{2}$ as $t_{1}$ and $t_{2}$, respectively. As the slug flow regime is unsteady, slug velocity may vary along the pipe causing it to have a variation in the measurements. The velocity of the slugs at six different locations were obtained. The first reference line was selected based on the location where the slug was first initiated, and the remaining reference lines were located within two meters after the first reference line. The velocity of the slugs at these locations were then averaged to indicate the mean slug translational velocity and their deviation factor was also calculated using Equation (15) to indicate the variation in the velocity.

$$
\begin{gathered}
U_{s}=\frac{\Delta x}{\Delta t}=\frac{\left(x_{2}-x_{1}\right)}{\left(t_{2}-t_{1}\right)} \\
s=\frac{\sum_{i-1}^{n}\left(x_{i}-\bar{x}\right)^{2}}{n-1}
\end{gathered}
$$

Notation $x_{i}$ is the result of the $i$ th measurement while $\bar{x}$ refers to the arithmetic mean of the $n$ results obtained.

\subsubsection{Slug Body Length to Diameter Ratio}

Typically, slug body length, $L_{b}$ can be computed using the multiplication of mixture velocity, $U_{s}$ of the fluids with the times taken for the slug nose, $t_{n}$ and tail, $t_{t}$ to pass through a reference line, as shown in Equation (16). Simulation work in Ref. [12] and experimental work in Ref. [31] used reference lines positioned at $54 \mathrm{D}$ (i.e., claimed that the flow is not fully developed) and 81D (fully developed slug) to measure slug body length. Knowing that the body of the slug is not constant throughout the flow, in this study, two types of slug body length were reported. The first category is the length of slug body for slugs which are similar to those reported in the literature; this is to ensure that there is a direct comparison to the published data. The second category is the maximum slug body for each slug regardless the position of reference line; this is to represent the longest possible 
slug body for a given model. Slug body length to diameter ratio, $L_{S}$ can be computed by dividing slug body length, $L_{b}$ with the diameter of the pipe.

$$
L_{b}=U_{s}\left(t_{t}-t_{n}\right)
$$

\subsubsection{Slug Frequency}

The number of slug bodies that meets the threshold, $a_{n}$ of 0.85 , moving at a given point per unit time is defined as slug frequency. This method is selected based on the work done by Ref. [22] in determining slug frequency. The expression for slug frequency, $f_{s}$ is simply the reciprocal of slug unit time, $T_{s}$ as follows:

$$
f_{s}=\frac{1}{T_{S}}
$$

The frequencies of slug obtained from simulation work were compared and validated against the following analytical expressions provided in Refs. [32-37]:

$$
\begin{gathered}
f_{s}=0.0434\left[\lambda_{L}\left(\frac{2.02}{D}+F r^{2}\right)\right]^{1.02} \\
f_{s}=0.088\left[F r\left(\frac{1.5}{J}+\lambda_{L}\right)\right]^{2} \\
f_{s}=\lambda_{L}\left(\frac{4.76 \times 10^{-3} J^{2}+0.035 J}{D}\right) \\
f_{s}=0.0037\left[\lambda_{L}\left(\frac{25}{g D}+F r^{2}\right)\right]^{9 / 5} \\
f_{s}=\frac{J_{G}}{D}\left(\frac{0.044 \lambda_{L}}{1-1.71 \lambda_{L}+0.7 \lambda_{L}^{2}}\right) \\
f_{s}=\frac{J_{G}}{D}\left(\frac{0.05 \lambda_{L}}{1-1.675 \lambda_{L}+0.768 \lambda_{L}^{2}}\right)
\end{gathered}
$$

where $J$ is the mixture superficial velocity, $F r$ is the mixture Froude number and $g$ is the gravitational acceleration. The phase homogeneous fraction, $\lambda_{k}$ can be determined using superficial velocity and mixture superficial velocity, as follows:

$$
\lambda_{k}=\frac{J_{k}}{J}
$$

\subsubsection{Pressure Gradient of Slug Flow}

Pressure gradient, $\Delta P$ was computed using the measurements of pressure at different pipe locations over distance (see Equation (25)). In this study, inlet and outlet of the pipe were used as the reference points for the measurement over time. The pressure gradient was calculated by the time average pressure drop over the entire length of the pipe section selected.

$$
\Delta P=\frac{p_{1}-p_{2}}{d_{1}-d_{2}}
$$

Notations $p_{1}$ and $p_{2}$ are the pressures at the outlet and inlet, respectively, while the notations $d_{1}$ and $d_{2}$ indicate the location of outlet and inlet longitudinally to represent the pressure along the pipe.

\section{Results and Discussion}

In this section, simulation results showing the influence on the evolution of slugs for various combinations of CFD settings are presented and discussed. Slug characteristics 
such as slug body length to diameter ratio, velocity, frequency, and pressure gradient of slug are then elaborated. The results in the present study were also compared with the published findings obtained via experimentation [17], simulation works using Ansys ${ }^{\circledR}$ [10] and STAR-CCM+ [23], and analytical equations [32-39].

\subsection{Influence of Various Combinations of CFD Settings on Development of Slugs}

Figure 6 shows the comparison on slug flow morphology between those published in the literature with that obtained in the present study using Altair ${ }^{\circledR}$ AcuSolve $^{\mathrm{TM}}$ (in this case, a snippet of model 4 was selected). The section that is filled with red color represents only water while those filled with blue color represents pure air. It can be seen that the main body of the fluids shows a good agreement with the experimental data [17], Ansys ${ }^{\circledR}$ model [10], and STAR-CCM+ model [23]; it can be seen that the computed slug body length for each slug closely followed the published data with a maximum difference in values of $1.63 \%$. A closer look at the results shows that several segments with gas bubbles are present in the experimental demonstration while no clear mixture of gas and liquid can be seen in the Altair ${ }^{\circledR}$ model. The VOF approach together with either piecewise linear reconstruction or high-resolution interface capturing schemes employed in Ansys ${ }^{\circledR}$ and STAR-CCM+ models seem to be able to track and model the convective transport of the multiphase mixture well. The level set approach in Altair ${ }^{\circledR}$ environment is limited to capturing moving interface well, and the task to capture bubbles generated by actual air entrainment is very difficult to achieve. Theoretically, in order to achieve that, the diffusive losses have to be kept to a minimum - this calls for the use of a smaller time step and mesh size. It should be noted that the number of elements used in this study is already double the elements employed by the published work using Ansys ${ }^{\circledR}$ and six times higher than number of elements in STAR-CCM+ works. Any attempt to further reduced the mesh size and time step would be futile as this would only increase the computational time and cost. It is believed that the level set in Altair ${ }^{\circledR}$ is good enough when tracking the fluid motion is of importance, while should the details on the phase's distribution be required, then the use of the CFD capabilities within Ansys ${ }^{\circledR}$ and STAR-CCM+ packages is recommended.

All computational models started with an equal 50-50 share between water and air. As the CFD packages solved them, the models started to demonstrate slug initiation. For models with standard level set, no slug seems to form within the computational time period, despite the implementation of perturbation at the inlet. This indicates that BFECC method needs to be coupled with the level set approach to capture internal boundary more accurately by removing errors induced by uneven gradient of the level set function. In terms of the slug initiation, model 6 (i.e., random perturbation, DES, and level set with BFECC) showed the first slug at time stamp equals to $1 \mathrm{~s}$, followed by model 3 at $1.62 \mathrm{~s}$, model 5 at $1.83 \mathrm{~s}$ and model 4 at $3.13 \mathrm{~s}$. It should be noted that the implementation of perturbation at the inlet is to artificially induce slug to form within a short simulation period. Instead of slug initiation time, the more important aspect of consideration should be on the characteristics of the resultant slug flow. The bounding boxes shown in Figures 7 and 8 highlight the slug body for each model. All models except models 1 and 2 managed to generate slug within $4 \mathrm{~s}$ simulation period. If the simulation's period for the models without the function of BFECC were to be extended to $9.8 \mathrm{~s}$, it can be seen that the slug managed to develop in the models. As shown in Figure 8, model 1 took longer time to initiate first slug when compared to other combinations of the models with BFECC. Regardless of the combinations of the CFD settings, it appears that the slugs could be reproduced sooner or later. However, the implementation of perturbations and BFECC to the level set function results in the formation of slug at a shorter computational time. 

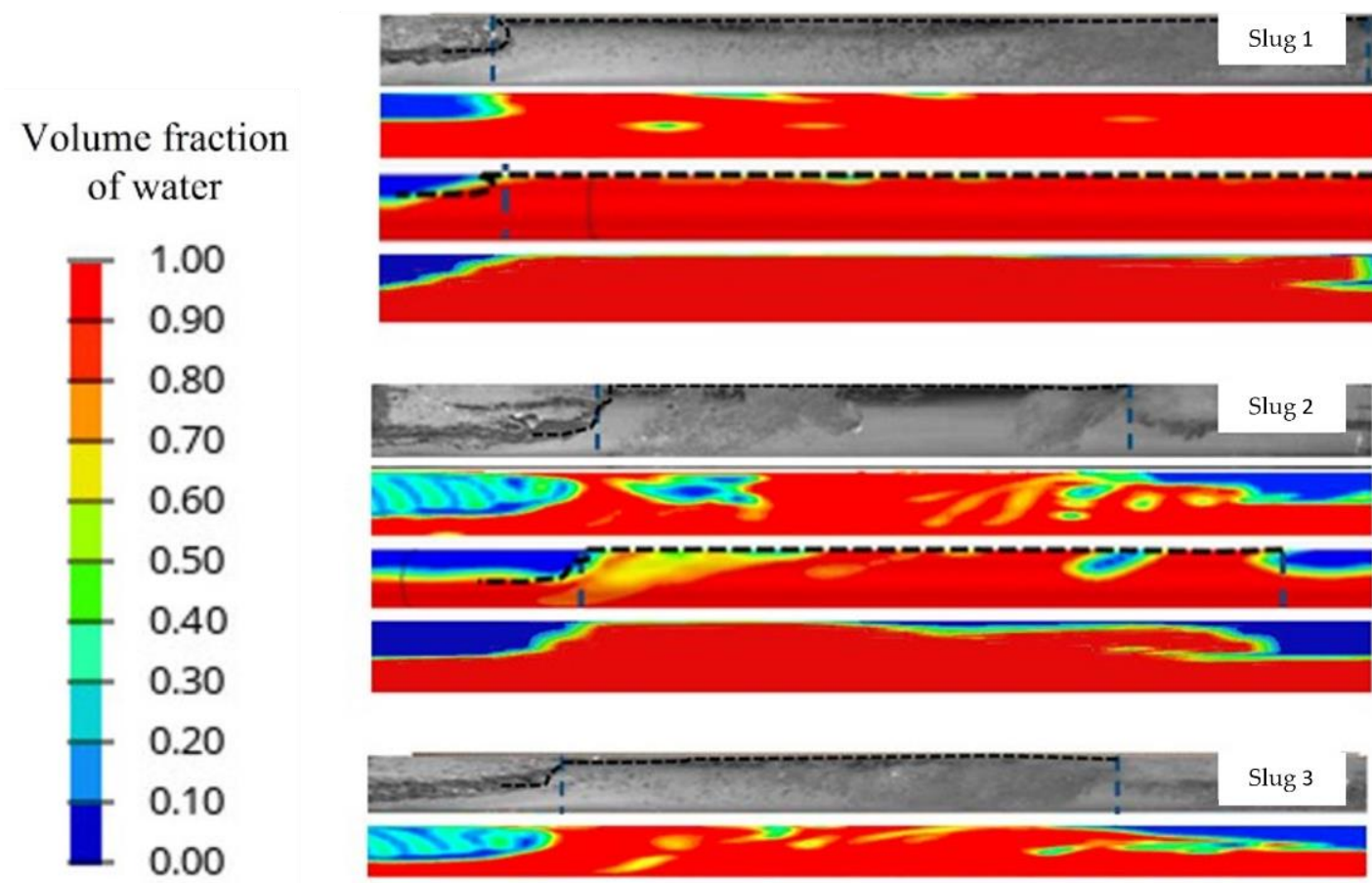

(a) $0.95 \mathrm{~m} \mathrm{(*)}^{*}$

(b) $0.95 \mathrm{~m} \mathrm{(*)}$

(c) $\left.0.95 \mathrm{~m}^{* *}\right)$

(d) $0.95 \mathrm{~m}$

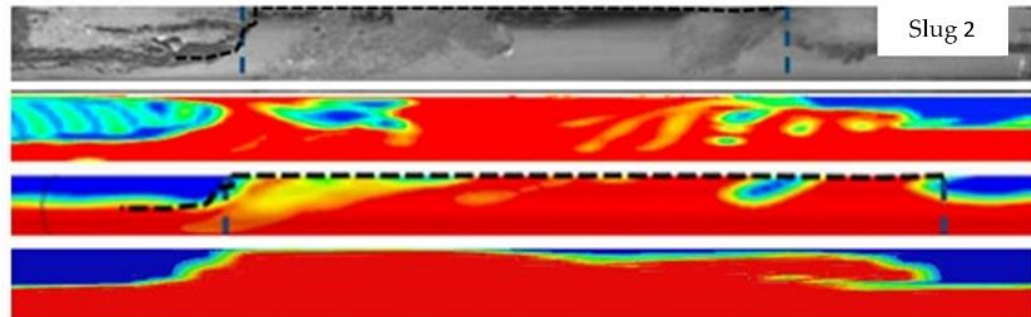

(a) $0.58 \mathrm{~m}\left(^{*}\right)$

(b) $0.58 \mathrm{~m} \mathrm{(*}^{*}$

(c) $0.58 \mathrm{~m}^{(* *}$

(d) $0.58 \mathrm{~m}$

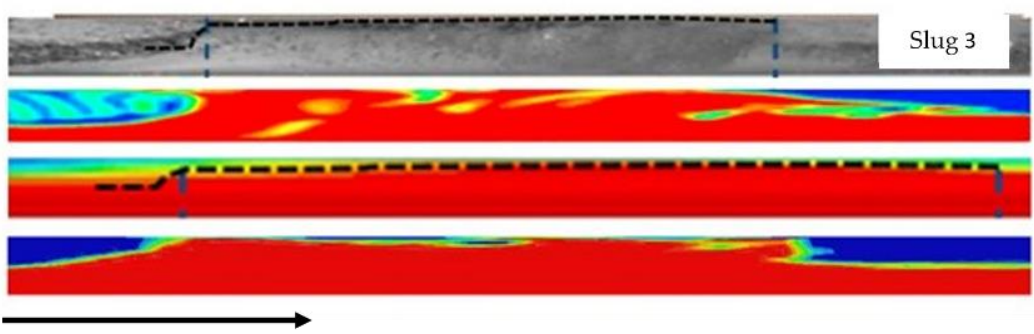

(a) $0.60 \mathrm{~m}\left(^{*}\right)$

(b) $\left.0.60 \mathrm{~m}^{*}\right)$

(c) $\left.0.61 \mathrm{~m}^{(* *}\right)$

(d) $0.60 \mathrm{~m}$

Flow direction

Figure 6. Comparison on slug flow morphology between (a) experimental result [17], (b) Ansys ${ }^{\circledR}$ simulation [10], (c) STAR-CCM+ simulation [23] and (d) Altair ${ }^{\circledR}$ AcuSolve ${ }^{\mathrm{TM}}$ simulation. Note that the slug body length values marked with * and ${ }^{* *}$ were extracted from Ref. [10], respectively.

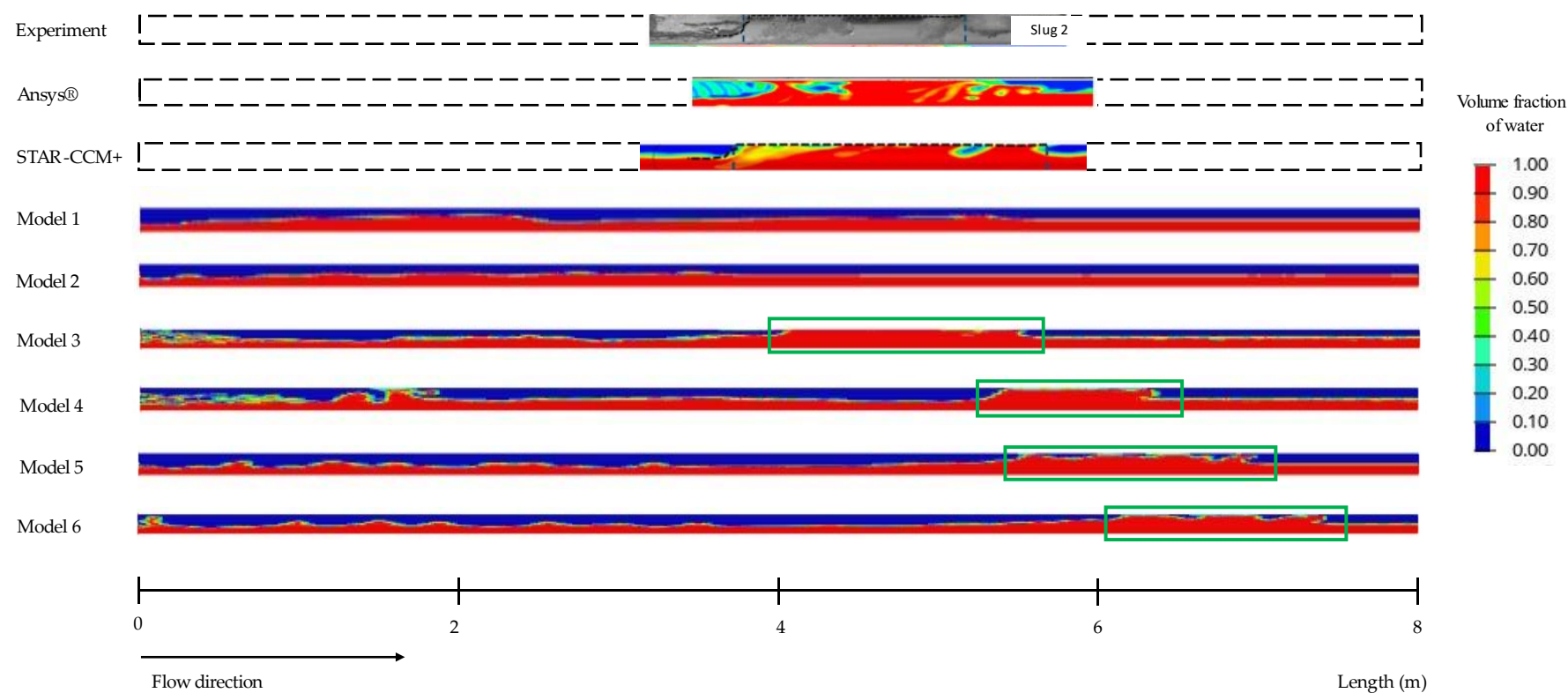

Figure 7. Flow morphology of each model implemented with various combinations of perturbations, multiphase and turbulence equations. 


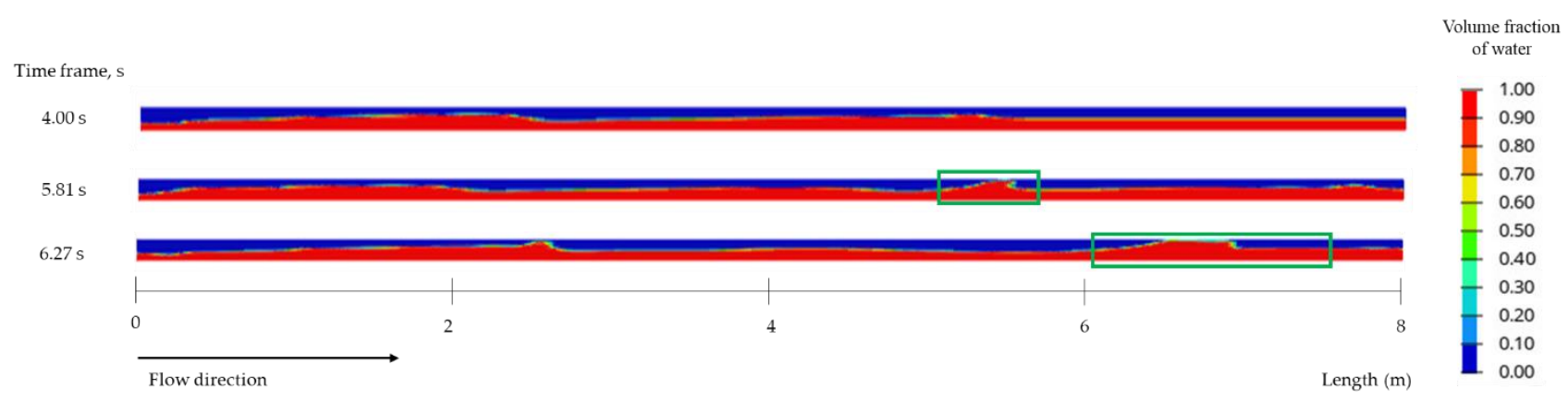

Figure 8. Flow morphology of model 1 which was extended up to simulation time of $9.8 \mathrm{~s}$.

\subsection{Average Slug Translational Velocity}

Figure 6 clearly shows that slugs were varying in lengths due to the unsteadiness nature of slug flow. This indirectly indicates that the translational slug velocity could vary along the pipe and thus an average value was presented to provide a better representation of the velocity. Table 5 summarizes the slug translational velocity for each model. It can be seen that there is no direct correlation between the time taken for the first appearance of slug to the corresponding slug translational velocity. As explained earlier, the implementation of perturbation and thus slug initiation is merely an artificial introduction to generate slug as fast as possible in CFD environment. After considering the deviation factor, among all models, model 3 exhibits the closest average slug translational velocity to the published experimental data [17] with a percentage difference of $1.15 \%$. In addition, other models obtained a range of $20 \%$ to $42 \%$ of percentage difference. Based on the data of average slug translational velocity, it is shown that, in comparison to DES, the Spalart Allmaras produced the lowest percentage difference when compared to the published experimental data [17].

Table 5. Slug translational velocity obtained by each model within $4 \mathrm{~s}$ computational time.

\begin{tabular}{cc}
\hline Model & Average Slug Translational Velocity (m/s) \\
\hline Experimental [17] & 4.39 \\
Ansys ${ }^{\circledR}[10]$ & 4.50 \\
STAR-CCM+ [23] & Not available \\
Model 1 & - \\
Model 2 & - \\
Model 3 & $3.64 \pm 0.70$ \\
Model 4 & $2.55 \pm 0.32$ \\
Model 5 & $2.95 \pm 0.44$ \\
Model 6 & $2.64 \pm 0.94$ \\
\hline
\end{tabular}

\subsection{Slug Body Length to Diameter Ratio}

Table 6 lists the comparison on slug body length to diameter ratio for various models using two quantification methods: (i) the length of slug body for slugs which are similar to those reported in the literature, and (ii) the maximum slug body for each slug regardless the position of reference line. When comparing the results of slug body length using Equation (16) and direct length measurement methods, there is not much difference between the results.

Model 4 obtained the closest slug body length at 81D reference line to those obtained using Ansys ${ }^{\circledR}$ [10] and experimental results [17] with percentage difference of $42.8 \%$. This model was set with random inlet perturbation, level set with BFECC as multiphase equation and Spalart Allmaras as turbulence equation. In this study, it was observed that various combinations of CFD parameters affect the initiation of slug within CFD environment. It appears that the slug can be formed at different location computationally depending on the selection of CFD parameters which then affect how early/late the slug 
can be formed, and the size of slug formed. Note that it has been shown that the physical slug behaviour can be mimicked closely in CFD environment, as illustrated in Figure 6, with a maximum difference in values of $1.63 \%$. However, the slug present at reference line $81 \mathrm{D}$ may vary according to the selection of CFD parameters. So, the method to quantify slug body length at reference line $81 \mathrm{D}$ is not quite suitable. As an alternative, the maximum values of slug body length to diameter ratio were quantified. This was done by tracking each slug body and measuring the maximum length of the slug body formed.

Table 6. Slug body length to diameter ratio, $L_{s}$ for each model.

\begin{tabular}{cccc}
\hline Model & $\begin{array}{c}\text { Slug Body Length to } \\
\text { Diameter Ratio, } L_{s} \text { at 81D } \\
\text { Using Equation (16) }\end{array}$ & $\begin{array}{c}\text { Slug Body Length to } \\
\text { Diameter Ratio, } L_{s} \text { at 81D } \\
\text { Using Direct Length } \\
\text { Measurement }\end{array}$ & $\begin{array}{c}\text { Maximum Slug Body Length } \\
\text { to Diameter Ratio, } L_{s} \\
\text { Observed Using Direct } \\
\text { Length Measurement }\end{array}$ \\
\hline $\begin{array}{c}\text { Experimental [17] } \\
\text { Ansys }{ }^{\circledR}[10]\end{array}$ & 7.240 & - & - \\
STAR-CCM+ [23] & 7.600 & - & - \\
Model 1 & 7.000 & - & - \\
Model 2 & - & - & - \\
Model 3 & - & 20.320 & 24.014 \\
Model 4 & 28.038 & 10.560 & 11.458 \\
Model 5 & 10.338 & 13.650 & 22.216 \\
Model 6 & 13.155 & 13.130 & 19.581 \\
\hline
\end{tabular}

Models 5 and 3 resulted in the longest slug body length to diameter ratio of 22.216 and 24.014, respectively. Both of these models were equipped with level set with BFECC as multiphase equation and Spalart Allmaras as turbulence equation. Slug model 6 and model 4 produced slug body length of 19.581 and 11.458 , respectively. Both of the models were set with level set with BFECC and DES. Based on the results in Table 6, it can be concluded that Spalart Allmaras as turbulence equation produced a longer slug body than DES. Apart from that, it is clearly shown that random inlet perturbation produced a higher slug body length to diameter ratio in comparison to that equipped with sinusoidal inlet perturbation for a given multiphase equation and turbulence equation.

\subsection{Slug Frequency}

The appearance of multiple slugs was monitored throughout the computational period. The present models developed using Altair ${ }^{\circledR}$ package can still predict the frequency of slug flow reasonably well as the results obtained are consistent with the published data. Based on the comparison on slug frequencies among various models listed in Table 7 , slugs in model 5 exhibited the closest frequency with the published experimental data in Ref. [17] with $11.24 \%$ difference while model 3 shows a good agreement with findings using STAR-CCM+ [23] with 3.57\% difference.

\subsection{Pressure Gradient}

In the industry, the pressure gradient can be used as an indicator to reflect the flow characteristics. The time series pressure gradient measurements of slug flow are quite complicated because of its intermittent nature. Despite that, it is possible and relatively easy to compare the mean pressure gradient along the test section. In this study, the pressure gradient was calculated by the time-averaged pressure drop over the entire length of the test section.

Figure 9 shows the summary of the pressure gradient for each model. The results show that the fluid systems experienced a drastic change in pressure gradient at time 3.0-3.5 s. This is because at this period the slugs were fully developed and thus causes a sudden pressure drop. The most stable pressure gradient models are shown by models 1 and 2 simply because the slugs were not developed in these models, resulting in a steady pressure gradient. It is noted that inlet perturbation in the form of sinusoidal function 
produced a more stable pressure gradient when compared to random inlet perturbation. This is because the change in agitation's amplitude applied at the inlet by sinusoidal perturbation is steadier than those of random perturbation.

Table 7. Slug frequency obtained by each model.

\begin{tabular}{cc}
\hline Model & Slug Frequency (Hz) \\
\hline Experimental [17] & 0.42 \\
Ansys ${ }^{\circledR}[10]$ & 0.49 \\
STAR-CCM+ [23] & 0.57 \\
Equation (18) [32] & 0.50 \\
Equation (19) [33] & 0.68 \\
Equation (20) [34] & 0.60 \\
Equation (21) [35] & 0.36 \\
Equation (22) [36] & 0.61 \\
Equation (23) [37] & 0.68 \\
Model 1 & - \\
Model 2 & - \\
Model 3 & 0.55 \\
Model 4 & 0.79 \\
Model 5 & 0.47 \\
Model 6 & 0.34 \\
\hline
\end{tabular}

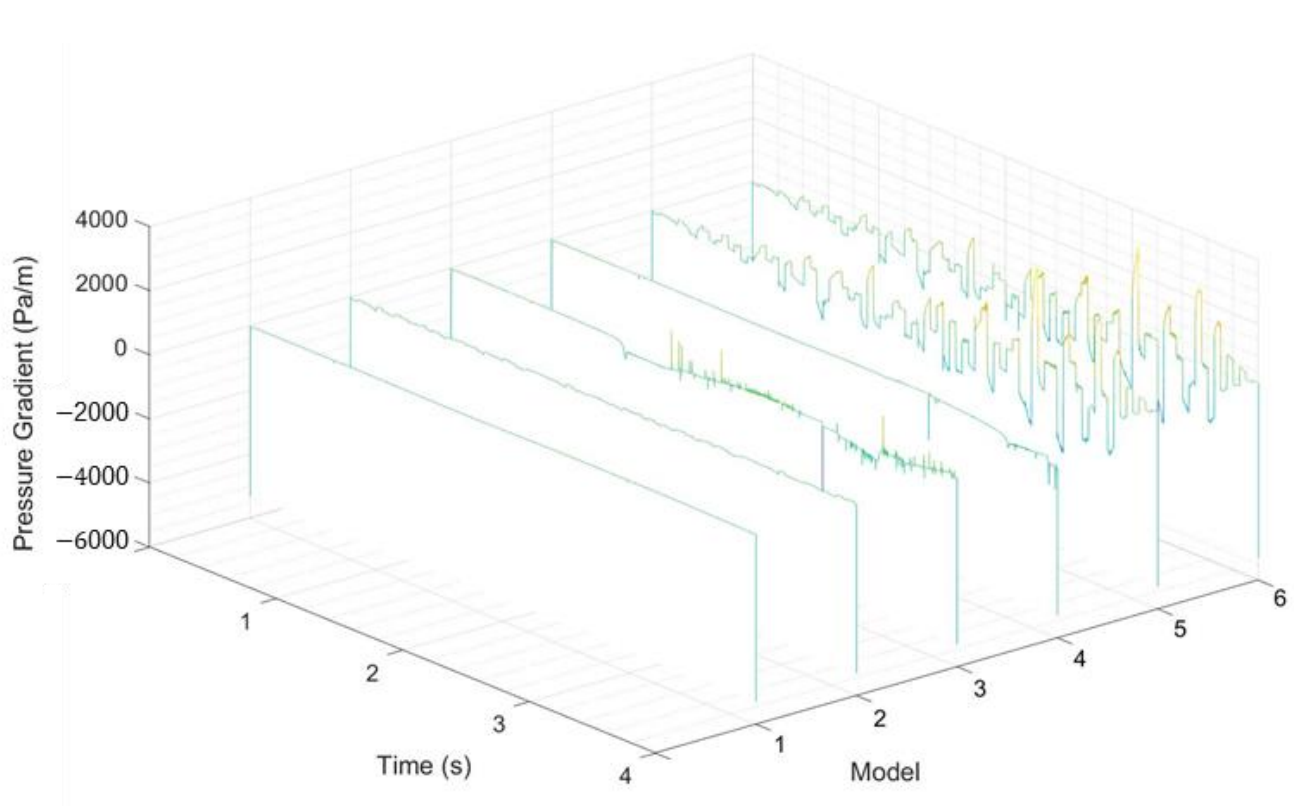

Figure 9. Compilation of pressure gradients for each model.

Relatively, models 5 and 6 which produced the most unstable pressure gradient in the fluid systems appeared to exhibit the lowest slug frequency. Similarly, model 4 which produced the most stable pressure gradient exhibited the highest slug frequency. It can be concluded that the stability of the pressure gradient in the fluid systems is directly proportional with slug frequency. This is because a drastic drop of pressure gradient in the systems would decrease the velocity of the fluids, hence reduces appearance/formation of slugs.

Overall, it was found that all models set up using Altair ${ }^{\circledR}$ package managed to exhibit the expected slug flow. The BFECC term was able to minimize the diffusive losses, hence develop slug faster in CFD environment when compared to the standard level set. Although Altair ${ }^{\circledR}$ could not track the details of the fluids mixing well such as the small bubbles near the boundary wall in comparison to other CFD codes [10,17], it has been demonstrated that Altair ${ }^{\circledR}$ could track the fluid main body reasonably well and its findings were in a 
good agreement with the published data. Both types of inlet perturbation applied in the system managed to develop the main slug body well. The presence of the deviation in the result was inevitable since the slug velocity varies across the length of the pipe. In addition, Spalart Allmaras turbulence equation was able to demonstrate the natural behaviour of the slugs better than DES since it produces the closest slug translational velocity when compared to published data $[10,17,20]$. Given that the frequency of the slugs produced in the present study showed a good consistency with those in Refs. [10,17,20,32-37], the models are assumed to be reasonably good for use in fluid-structure interaction modelling such as pipe vibrational analysis.

\section{Conclusions}

Selection of inlet perturbations, multiphase equation and turbulence equation may affect the development of slug flow using computational fluid dynamic simulation tools. The inlet perturbation, such as sinusoidal and random perturbations, plays an essential role in inducing slug formation. Multiphase equations such as volume of fluid and level set are used to track and capture the gas-liquid immiscible interface. Similarly, turbulence equations such as Spalart Allmaras (SA), Detached Eddy Simulations (DES), and k-epsilon can be used to predict the evolution of turbulence within the flow. At present, no direct comparison is available in the literature on the selection of (i) types of inlet perturbations, (ii) choice of multiphase equation, and (iii) turbulence equation on the development of slug flow using Altair computational package. This article aims to investigate the effects of the selection of inlet perturbations, multiphase equations, and turbulence equations on slug flow characteristics using Altair ${ }^{\circledR}$ AcuSolve ${ }^{\mathrm{TM}}$. The slug flow characteristics of interest include slug morphology, body length-to-diameter ratio, velocity, frequency, and pressure gradient. The followings are the concluding remarks:

i $\quad$ Altair $^{\circledR}$ AcuSolve ${ }^{\mathrm{TM}}$ which is based on finite element method could model slug flow and characterize its fluid characteristics with a good agreement to published experimental data and findings by CFD codes that employ finite volume method. However, it should be noted that level set approach offered in Altair $^{\circledR}$ AcuSolve ${ }^{\mathrm{TM}}$ has a limitation in modelling the convective transport of the multiphase mixture. AcuSolve ${ }^{\mathrm{TM}}$ lacks high resolution/reconstruction schemes to capture bubbles generated by actual air entrainment despite its ability to track the main fluid body's motion successfully.

ii In comparison to standard level set, level set coupled with back-and-forth error compensation and correction could initiate the slug formation at a shorter computational time. Coupling of back-and-forth error compensation and correction with level set function can capture internal boundary more accurately by reducing errors caused by numerical diffusion in the transport of the level set.

iii The presence of the inlet perturbation (either sinusoidal or random) helps develop the slug flow in the computational environment. Having said this, sinusoidal function produced a more stable pressure gradient throughout the pipe when compared to random inlet perturbation.

iv The Spalart Allmaras turbulence equation was able to mimic experimental conditions better than DES as it produced the closest slug translational velocity compared to the published data.

Author Contributions: Conceptualization, M.S.A.B. and N.S.; methodology, M.S.A.B., N.S. and W.P.K.S.; software, M.S.A.B. and N.S.; validation, M.S.A.B. and N.S.; formal analysis, M.S.A.B. and N.S.; resources, N.S., S.T.S.; data curation, M.S.A.B. and N.S.; writing-original draft preparation, M.S.A.B. and N.S.; writing-review and editing, M.S.A.B., N.S., W.P.K.S., S.T.S., R.S., M.A.S.; supervision, N.S. and W.P.K.S.; project administration, N.S.; funding acquisition, N.S., R.S., M.A.S. All authors have read and agreed to the published version of the manuscript.

Funding: The authors would like to acknowledge that this research is partially funded by Yayasan Universiti Teknologi PETRONAS via Fundamental Research Grant (YUTP-FRG) 015LC0-237 and ICRF-UTP-UNG 015ME0-156. 
Institutional Review Board Statement: Not applicable.

Informed Consent Statement: Not applicable.

Data Availability Statement: Data generated from this study can be found at: [shorturl.at/lsDUY].

Acknowledgments: The authors are thankful to Universiti Teknologi PETRONAS for providing financial support through graduate assistantship scheme. A special appreciation is also extended to Michael Tanguay from Altair Engineering for his feedback and comments on the preparation of the manuscript.

Conflicts of Interest: The authors declare no conflict of interest.

\section{Abbreviations}

FIV Fluid-induced vibration

CFD Computational fluid dynamics

LES Large Eddy simulation

RANS Reynold-averaged Navier Stokes

DES Detached Eddy simulations

SA Spalart Allmaras

VOF Volume of fluid

BFECC Back and forth error compensation and correction

GCI Grid convergence index

\section{Nomenclature}

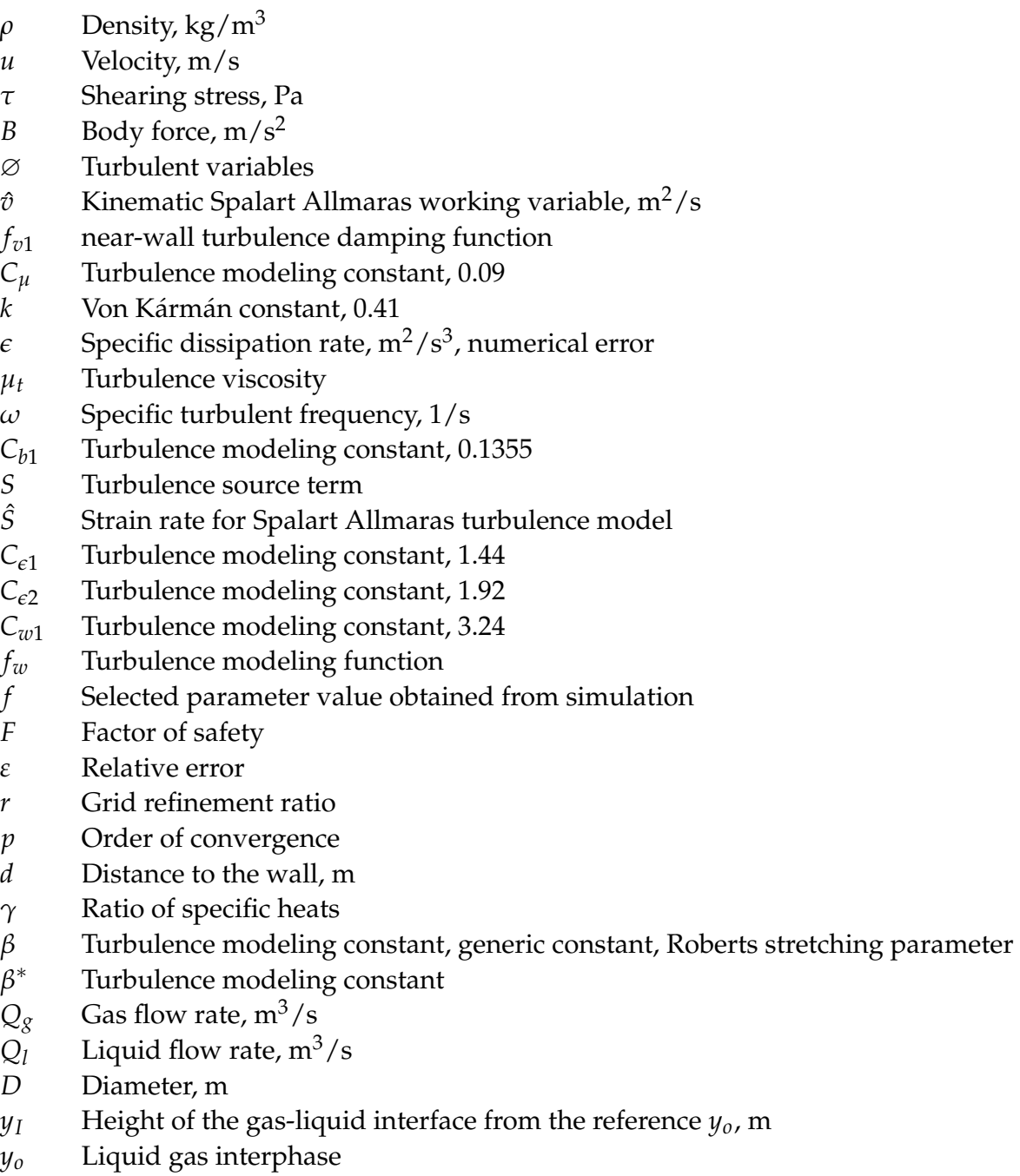




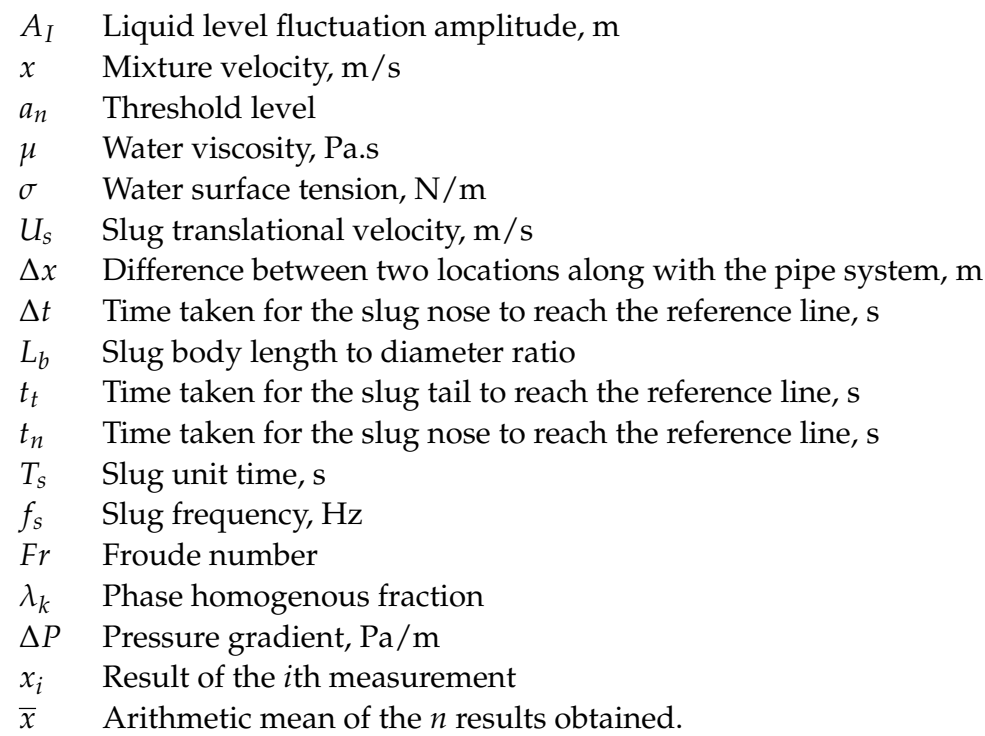

\section{References}

1. Zhu, H.; Gao, Y.; Zhao, H. Experimental Investigation of Slug Flow-Induced Vibration of a Flexible Riser. Ocean Eng. 2019, 189, 106370. [CrossRef]

2. Wang, L.; Yang, Y.; Li, Y.; Wang, Y. Dynamic Behaviours of Horizontal Gas-Liquid Pipes Subjected to Hydrodynamic Slug Flow: Modelling and Experiments. Int. J. Press. Vessel. Pip. 2018, 161, 50-57. [CrossRef]

3. Lun, I.; Calay, R.K.; Holdo, A.E. Modelling Two-Phase Flows Using CFD. Appl. Energy 1996, 53, 299-314. [CrossRef]

4. Thomas, F. Numerical Simulation of Slug Flow Regime for An Air Water Two-Phase Flow in Horizontal Pipes. In Proceedings of the 11th International Topical Meeting on Nuclear Reactor Thermal Hydraulics (NURETH 11), Avignon, France, 2-6 October 2005.

5. Parvareh, A.; Rahimi, M.; Alizadehdakhel, A.; Alsairafi, A. CFD and ERT Investigations on Two-Phase Flow Regimes in Vertical and Horizontal Tubes. Int. Commun. Heat Mass Transf. 2010, 37, 304-311. [CrossRef]

6. Labois, M.; Narayanan, C.; Lakehal, D. Advances in the Large-Eddy and Interface Simulation (LEIS) of Interfacial Multiphase Flows in Pipes. Prog. Comput. Fluid Dyn. 2012, 12, 153-163.

7. Mo, S.; Ashrafian, A.; Barbier, J.-C.; Johansen, S.T. Quasi-3D Modelling of Two-Phase Slug Flow in Pipes. J. Comput. Multiph. Flows 2014, 6, 1-12. [CrossRef]

8. Tanveer, N.M.; Mohanraj, C.; Jegadeesan, K.; Maruthupandiyan, S. Comparative Studies on Various Turbulent Models with Liquid Rocket Nozzle through Computational Tool. Adv. Mater. Res. 2014, 984, 1204-1209. [CrossRef]

9. Spalart, P.; Allmaras, S. A One-Equation Turbulence Model for Aerodynamic Flows, in 30th Aerospace Sciences Meeting and Exhibit. In 30th Aerospace Sciences Meeting and Exhibit; AIAA ARC: Reston, VA, USA, 1992.

10. Pao, W.; Sam, B.; Nasíf, M.; Norpiah, R. Numerical Validation of Gas-Liquid Slug Flow Inside Horizontal Pipe. J. Fundam. Appl. Sci. 2018, 9, 662. [CrossRef]

11. Hadia, H. Computational Fluid Dynamics (CFD) to Simulate Slug Flow in Horizontal Pipeline and Annular Pipe; Memorial University of Newfoundland: St. John's, NL, Canada, 2018.

12. Ban, S.; Pao, W.; Nasif, M.S. Numerical Simulation of Two-Phase Flow Regime in Horizontal Pipeline and Its Validation. Int. J. Numer. Methods Heat Fluid Flow 2018, 28, 1279-1314. [CrossRef]

13. Ansys, F. Theory Guide 17.2; Ansys Inc.: Canonsburg, PA, USA, 2016.

14. Tu, S.; Aliabadi, S.; Patel, R.; Watts, M. An Implementation of the Spalart-Allmaras DES Model in an Implicit Unstructured Hybrid Finite Volume/Element Solver for Incompressible Turbulent Flow. Int. J. Numer. Methods Fluids 2009, 59, 1051-1062. [CrossRef]

15. Wilcox, D. Turbulent Modelling for CFD; DCW Industries: La Canada, CA, USA, 2004.

16. Pao, W.; Sam, B.; Nasif, M.S.; Norpiah, R.B. Numerical Validation of Two-Phase Slug Flow and its Liquid Holdup Correlation in Horizontal Pipeline. Key Eng. Mater. 2017, 740, 173-182. [CrossRef]

17. Mohmmed, A. Effect of Slug Two-Phase Flow on Fatigue of Pipe Material. Ph.D. Thesis, Universiti Teknologi Petronas, Perak, Malaysia, 2016.

18. Abdul Karim, S.A.; Memon, Z.; Pao, W.; Hashim, F.M. Preliminary Results of Numerical Simulation of Slug Flow in a Regular T-Junction. In MATEC Web of Conferences; EDP Sciences: Les Ulis, France, 2018; p. 225.

19. Pao, W.; Hon, L.; Saieed, A.; Ban, S. Numerical Simulation of Two-Phase Slug Flow with Liquid Carryover in Different Diameter Ratio T-Junction. J. Phys. 2017, 908, 12037. [CrossRef]

20. Al-Kayiem, H.H.; Al-Hashimy, Z.I.; Time, R.W.; Kadhim, K.Z. Comparative Experimental and Numerical Investigations on the Characteristics of Air/Water Slug Flow in Horizontal Pipes. J. Adv. Res. Fluid Mech. Therm. Sci. 2020, 65, $264-285$.

21. Kim, B.; Liu, Y.; Llamas, I.; Rossignac, J.R. FlowFixer: Using BFECC for Fluid Simulation; Georgia Institute of Technology: Atlanta, GA, USA, 2005; pp. 51-56. 
22. Schmelter, S.; Knotek, S.; Olbrich, M.; Fiebach, A.; Bär, M. On the Influence of Inlet Perturbations on Slug Dynamics in Horizontal Multiphase Flow-A Computational Study. Metrologia 2021, 58, 014003. [CrossRef]

23. Mohmmed, A.O.; Al-Kayiem, H.H.; Osman, A.B.; Sabir, O. One-Way Coupled Fluid-Structure Interaction of Gas-Liquid Slug Flow in a Horizontal Pipe: Experiments and Simulations. J. Fluids Struct. 2020, 97, 103083. [CrossRef]

24. De Schepper, S.C.K.; Heynderickx, G.J.; Marin, G.B. CFD Modeling of All Gas-Liquid and Vapor-Liquid Flow Regimes Predicted by the Baker Chart. Chem. Eng. J. 2008, 138, 349-357. [CrossRef]

25. Slater, J.; Dudek, J.; Tatum, K. The NPARC Alliance Verification and Validation Archive; The American Society of Mechanical Engineers: New York, NY, USA, 2000; p. 251.

26. Montini, M. Closure Relations of the One-Dimensional Two-Fluid Model for the Simulation of Slug Flows. Ph.D. Thesis, Imperial College London, London, UK, 2011.

27. Manolis, I.G. High Pressure Gas-Liquid Slug Flow. Ph.D. Thesis, Imperial College London, London, UK, 1995.

28. King, M.J.S. Experimental and Modelling Studies of Transient Slug Flow. Ph.D. Thesis, Imperial College London, London, UK, 1998.

29. Hale, C.P. Slug Formation, Growth and Decay in Gas-Liquid Flows. Ph.D. Thesis, Imperial College London, London, UK, 2001.

30. Pan, J. Gas Entrainment in Two-Phase Gas-Liquid Slug Flow. Ph.D. Thesis, Imperial College London, London, UK, 2010.

31. Mohmmed, A.O.; Nasif, M.S.; Al-Kayiem, H.H.; Time, R.W. Measurements of Translational Slug Velocity and Slug Length Using an Image Processing Technique. Flow Meas. Instrum. 2016, 50, 112-120. [CrossRef]

32. Heywood, I.N.; Richardson, J.F. Slug Flow of Air-Water Mixtures in a Horizontal Pipe: Determination of Liquid Holdup by $\gamma$-ray Absorption. Chem. Eng. Sci. 1979, 34, 17-30. [CrossRef]

33. Nydal, O.J. An Experimental Investigation on Slug Flow. Ph.D. Thesis, University of Oslo, Oslo, Norway, 1991.

34. Jepson, W.P.; Taylor, R.E. Slug Flow and Its Transitions in Large-Diameter Horizontal Pipes. Int. J. Multiph. Flow 1993, 19, 411-420. [CrossRef]

35. Manolis, I.G.; Mendes-Tatsis, M.A.; Hewitt, G.F. The Effect of Pressure on Slug Frequency in Two-Phase Horizontal Flow. In Multiphase Flow; Elsevier: Amsterdam, The Netherlands, 1995; pp. 347-354.

36. Fossa, M.; Guglielmini, G.; Marchitto, A. Intermittent Flow Parameters from Void Fraction Analysis. Flow Meas. Instrum. 2003, 14, 161-168. [CrossRef]

37. Wang, X.; Guo, L.; Zhang, X. An Experimental Study of the Statistical Parameters of Gas-Liquid Two-Phase Slug Flow in Horizontal Pipeline. Int. J. Heat Mass Transf. 2007, 50, 2439-2443. [CrossRef]

38. Zabaras, G.J. Prediction of Slug Frequency for Gas-Liquid Flows. SPE J. 1999, 5, 252-258. [CrossRef]

39. Al-Safran, E. Probabilistic Modeling of Slug Frequency in Gas/Liquid Pipe Flow Using Poisson Probability Theory. In Proceedings of the 8th North American Conference on Multiphase Technology, Banff, AB, Canada, 20-22 June 2012. 